\title{
Errors in the Administration Technique of Insulin Pen Devices: A Result of Insufficient Education
}

Teresa H. Truong • Trang T. Nguyen • Becky L. Armor •

Jamie R. Farley

Received: June 22, 2016 / Published online: March 4, 2017

(C) The Author(s) 2017. This article is published with open access at Springerlink.com

\section{ABSTRACT}

Insulin is a high-alert medication in both inpatient and outpatient settings. Insulin can cause significant harm when administered in error. Despite advancements in insulin pen technology, errors in the administration technique remain an issue. Although various factors can contribute to administration errors, lack of education on how to operate these devices is one of the most common reasons they occur. As such, the mechanical technique used by the patient needs to be continually assessed in order to reinforce education where needed. We describe three unique patient cases that depict incorrect administration techniques when using pen devices and the consequences that could have resulted from these errors. These cases involve the use of a syringe instead of a pen needle, injecting without removing the inner cap, and dialing the pen back down instead of pushing the plunger. Although pen devices are relatively simple to use, this article reinforces the need for continual assessment of

Enhanced content To view enhanced content for this article go to http://www.medengine.com/Redeem/ 5297F06060B06655.

T. H. Truong $(\varangle)$ · T. T. Nguyen · B. L. Armor • J. R. Farley

University of Oklahoma College of Pharmacy,

Oklahoma, USA

e-mail: teresa-truong@ouhsc.edu and education about insulin administration. The teach-back method is an approach that can be used to assess a patient's technique and re-educate them at every available opportunity to reduce the risk of administration errors, which can result in complications and hospitalizations.

Keywords: Insulin; Insulin administration; Patient education; Pen devices; Teach-back method

\section{INTRODUCTION}

Among the many people who have diabetes, approximately 6 million use insulin to control their blood glucose [1]. In ten years, the use of insulin in conjunction with oral therapy has increased from $11.5 \%$ to $13.0 \%$ [2], likely due to its earlier introduction during the course of treatment for those with type 2 diabetes. This keeps insulin consistently in the top 200 dispensed medications in the United States [3].

Correct administration of insulin is essential since employing an incorrect technique may lead to hyperglycemic crisis or severe hypoglycemia, necessitating emergency department (ED) visits. Geller et al. used national surveillance data and estimated that 97,648 ED visits occur annually due to insulin-related hypoglycemia, with almost one-third resulting in 
hospital admission. They also found that severe neurologic sequelae occurred in $60.6 \%$ of these visits, and blood glucose levels of less than $50 \mathrm{mg} / \mathrm{dL}$ were documented in $53.4 \%$ of the cases [4]. More broadly, according to the American Diabetes Association, about 282,000 ED visits in 2011 were due to hypoglycemia, and approximately 175,000 ED visits were due to a hyperglycemic crisis [1].

Due to these risks, insulin is continually listed on the Institute for Safe Medication Practice's (ISMP's) list of high-alert medications in both acute care settings and community/ambulatory care settings [5]. The ISMP high-alert medications are those that can cause significant harm, including death, to a patient when used in error [5]. Insulin errors can occur at each step of the medication use process, including prescribing, transcribing, dispensing, and administration. The majority of these errors occur during administration [6].

Historically, insulin was injected using only vial and syringe. This method continues to be used today, albeit at a much lower rate. Today, more than $60 \%$ of insulin users worldwide are using insulin pen devices to administer insulin [7]. Compared to vial and syringe, insulin pens tend to be more accurate, more comfortable, less obtrusive, and easier and more convenient to use due to advances in the technology [8-13]. These technological advances have resulted in increased patient preference of these devices, improved insulin adherence, enhanced quality of life, and decreased overall health care costs [10-14]. Despite these improvements, the way in which they are operated by patients needs to be assessed in order to identify areas in which education should be reinforced.

Here we present three patient cases in which errors in insulin pen technique and administration negatively impacted the patients' diabetes control and could have resulted in more serious health issues. These types of insulin pen administration errors were previously unreported.

\section{CASES}

Case 1 A 44-year-old Caucasian male with type 1 diabetes presented to the pharmacotherapy clinic for routine follow-up. While providing a medication history, the patient reported that he did not not like insulin pens. He stated, "I find them to be a hassle compared to vial and syringe." In his electronic medical record, a short-acting insulin pen device and $1 / 2 \mathrm{cc}$ insulin syringes were on his medication list, but no insulin pen needles. When asked to demonstrate his use of the insulin pen, he took an insulin syringe, injected the syringe into his pen device, dialed the device to 5 units and pushed the plunger. He believed that he was filling the insulin syringe with 5 units of insulin by doing this, and then used the syringe to inject his insulin, which was essentially empty.

Case 2 A 65-year-old African American female diagnosed with type 2 diabetes presented to the pharmacotherapy clinic for initial diabetes assessment. She was diagnosed 6 months prior to the visit with an A1C finding of $14.8 \%(138 \mathrm{mmol} / \mathrm{mol})$. Glipizide $5 \mathrm{mg}$ daily and insulin detemir flexpen 10 units twice daily were started at diagnosis, and insulin detemir had since been increased to 20 units in the morning and 30 units in the evening while glipizide remained at $5 \mathrm{mg}$ daily. When asked if the patient had any difficulty injecting the insulin pen device, she reported that it "spills out of the skin" before the entire dose is given. Patient was then asked to demonstrate her technique. She placed the pen needle on the pen device and securely screwed it on. She removed the outer cap of the needle, then dialed the device up to 20 units and attempted to inject without removing the inner cap. Hence, the needle was never injected and insulin flowed out of the inner cap. Despite not receiving any insulin for 6 months, her blood glucose readings had dramatically improved and were at goal with an updated A1C of $6.6 \%$ ( $49 \mathrm{mmol} / \mathrm{mol})$, likely due to extensive lifestyle modifications and glipizide initiation. After this discovery, insulin detemir was discontinued. Blood glucose remained controlled for at least 12 months following its discontinuation.

Case 3 A 55-year-old Hispanic female with type 2 diabetes presented to the pharmacotherapy clinic for routine follow-up regarding bolus insulin initiation 2 weeks prior. She had been on basal insulin via vial and syringe for a 
few years with insufficient results. Her primary care provider initiated bolus insulin via pen device for ease of use and transportation; however, no education was given on the injection technique since the patient had previously taken insulin. The patient reported that her blood sugars were not improving and she wanted to know how long each pen should last. After visual inspection of the pen device, it was evident that no insulin had been dispensed yet. When asked to demonstrate her injection technique, the patient properly placed the needle on the device and dialed the dose to 10 units. She then removed the outer and inner caps of the needle and inserted it. Instead of pushing the plunger button to dispense the medication, she dialed the dose down from 10 to 0 by twisting the end of the pen device as she had been doing at home the previous 2 weeks.

Informed consent was obtained verbally from the patients included in this manuscript.

\section{DISCUSSION}

The above cases expose the danger of incorrect administration techniques. In the first case, the patient with type 1 diabetes had essentially no bolus coverage due to the inappropriate use of a syringe instead of a pen needle, and was at risk for diabetic ketoacidosis since patients with type 1 diabetes lack endogenous insulin production and rely on injectible insulin products. Another concern over the use of a syringe and withdrawing insulin from a pen is the evolution of more concentrated insulins in pen form. This particular patient had a U-100 formulation; however, it highlights the importance of proper education on pen use. In the second case, the incorrect use of the insulin pen was, ironically, advantageous to the patient, as her A1C had reached the goal without her actually needing to inject any insulin. Had she injected the insulin correctly, the patient would have been at risk for severe hypoglycemia. Similar to the first case, the patient in case 3 was not injecting any insulin at all due to incorrect technique. The error was discovered and corrected quickly, thereby limiting the risk of titrating the dose to inadvertent nonadherence. In all three of these cases, administration errors were discovered by having the patient demonstrate how they operated their pen device. These cases highlight the importance of education on insulin administration, assessing technique, and re-educating in cases where understanding is lacking, even with a product that is seemingly relatively simple.

With over 1700 different types of devices approved by the U.S. Food and Drug Administration, ensuring that patients receive proper education on the use of these devices is vital [15]. The use of insulin has several components that must be taught and learned, including insulin storage and suspension, injection site care, the injection process, insulin pen use, skin folds, injection site rotation, and needle use and length [16]. Other considerations that are taught when using insulin include injection complications, proper disposal of the injection material, hypoglycemia, and monitoring [16]. The amount of information given to a patient when initiating insulin likely results in an inability to retain all of the information taught. A cross-sectional study that aimed to identify the most common incorrect self-administration techniques for insulin found that $21 \%$ of participants reported a lack of knowledge of the steps involved in insulin administration: on average, $61 \%$ of the steps were performed correctly [17]. Additionally, the Insulin Injection Technique Questionnaire developed by De Coninck et al. was used to query patients on how they inject insulin. Several administration errors were discerned, including injecting into the same site, injecting into lipohypertrophic lesions, needle reuse, injecting through clothes, and not mixing cloudy insulins before use. When asked why these errors occurred, many patients reported they did not recall learning the skills to inject insulin [18]. Whether patients were not taught these skills or whether they simply forgot due to the amount of information given to them is unknown. Nevertheless, providers should assess administration technique and repeat the education until patients understand the standard technique and why it matters. Nakatani et al. aimed to evaluate the impact of re-education on insulin injection technique in 87 insulin-treated patients. The 
results showed that there was a significant decrease in HbA1c and glycoalbumin levels in all 87 patients, with patients with a poor initial understanding of the insulin injection technique gaining the most from the re-education [19]. This study illustrates how important it is to provide proper education, including re-education, on the self-administration of insulin in order to reduce medication errors and prevent complications.

A fundamental approach to assessing insulin administration technnique is the teach-back method. The teach-back method is an intervention that is used to assess learners' skills and understanding by having the patient explain to the provider, in their own words, what they learned after being introduced to the concept for the first time. The teach-back method also helps to assess the effectiveness of the educator's ability to convey concepts to the learner $[20,21]$. It permits immediate remediation and clarification of skills and concepts if they are not properly understood. According to the experiences of frontline pharmacists, more than $98 \%$ of the 66 patients in the study agreed that they felt confident about performing subcutaneous insulin injections according to guidelines after being instructed via the teach-back method [21]. Indeed, the Institute for Ethics and the Agency for Healthcare Research and Quality promote the teach-back method as a "best practice" to enhance patient knowledge and improve patient outcomes [22, 23].

\section{CONCLUSIONS}

Although pen devices have been shown to provide greater accuracy and are associated with greater treatment satisfaction, these cases demonstrate that problems still exist, even with a product that is seemingly relatively simple to use. This article reinforces the need for repeated patient education and assessment of insulin administration. Patients must understand best practices and why they matter in order to avoid adverse effects of insulin. The teach-back method is a fundamental approach in which assessment and re-education is performed at every available opportunity to reduce complications and hospitalization rates due to poor injection technique.

\section{ACKNOWLEDGEMENTS}

No funding or sponsorship was received for this case series or the publication of this article. All authors listed meet the International Committee of Medical Journal Editors (ICJME) criteria for authorship, take responsibility for the integrity of this work as a whole, and have given final approval of the version to be published.

Dr. Teresa Truong wrote the manuscript, researched data, and reviewed/edited the manuscript. Dr. Trang Nguyen wrote the manuscript and researched the data. Dr. Becky Armor wrote the manuscript and reviewed/edited the manuscript. Dr. Jamie Farley wrote the manuscript and reviewed/edited the manuscript.

Disclosures. Teresa H. Truong, Trang T. Nguyen, Becky L. Armor, and Jamie R. Farley have nothing to disclose.

Compliance with Ethics guidelines. The authors received consent from all patients included in this commentary.

Data Availability. Data sharing is not applicable to this article as no datasets were generated or analyzed.

Open Access. This article is distributed under the terms of the Creative Commons Attribution-NonCommercial 4.0 International License (http://creativecommons.org/licenses/ by-nc/4.0/), which permits any noncommercial use, distribution, and reproduction in any medium, provided you give appropriate credit to the original author(s) and the source, provide a link to the Creative Commons license, and indicate if changes were made. 


\section{REFERENCES}

1. American Diabetes Association. Fast facts data and statistics about diabetes. Article online. 2015. Available from: http://professional.diabetes.org/sites/ professional.diabetes.org/files/media/Fast_Facts_122015a_1.pdf. Accessed 7 Feb 2017.

2. Centers for Disease Control and Prevention. Diabetes public health resource. Age-adjusted percentage of adults with diabetes using diabetes medication, by type of medication, United States, 1997-2011. Article online. 2013. Available from: http://www.cdc.gov/diabetes/statistics/meduse/fig2. htm. Accessed 7 Feb 2017.

3. Pharmacy Times. Top drugs of 2013. Article online. 2014. Available from: http://www.pharmacytimes. com/publications/issue/2014/July2014/Top-Drugsof-2013. Accessed 7 Feb 2017.

4. Geller AI, Shehab N, Lovegrove MC, et al. National estimates of insulin-related hypoglycemia and errors leading to emergency department visits and hospitalizations. JAMA Intern Med. 2014;174(5):678-86.

5. Institute for Safe Medication Practices. ISMP high-alert medications. Article online. 2014. Available from: http://www.ismp.org/Tools/highAlertMedicationLists. asp. Accessed 7 Feb 2017.

6. Cousins D, Rosario C, Scarpello J. Insulin, hospitals and harm: a review of patient safety incidents reported to the National Patient Safety Agency. Clin Med. 2011;11:28-30.

7. Perfetti R. Reusable and disposable insulin pens for the treatment of diabetes: understanding the global differences in user preference and an evaluation of inpatient insulin pen use. Diabetes Technol Ther. 2010;12(Suppl 1):S79-85.

8. Molife C, Lee LJ, Shi L, Sawhney M, Lenox SM. Assessment of patient-reported outcomes of insulin pen devices versus conventional vial and syringe. Diabetes Technol Ther. 2016;11:529-38.

9. Cuddihy RM, Borgman SK. Considerations for diabetes: treatment with insulin pen devices. Am J Ther. 2013;20(6):694-702.

10. Korytkowski M, Bell D, Jacobsen C, Suwannasari R. A multicenter, randomized, open-label, comparative, two-period crossover trial of preference, efficacy, and safety profiles of a prefilled, disposable pen and conventional vial/syringe for insulin injection in patients with type 1 or 2 diabetes mellitus. Clin Ther. 2003;25(11):2836-48.
11. Korytkowski M, Niskanen L, Asakura T. FlexPen: addressing issues of confidence and convenience in insulin delivery. Clin Ther. 2005;27(suppl B):S89-100.

12. Magwire ML. Addressing barriers to insulin therapy: the role of insulin pens. Am J Ther. 2011;18(5):392-402.

13. Graff MR, McClanahan MA. Assessment by patients with diabetes mellitus of two insulin pen delivery systems versus a vial and syringe. Clin Ther. 1998;20:486-96.

14. Grabner M, Chu J, Raparla S, Quimbo R, Zhou S, Conoshenti J. Clinical and economic outcomes among patients with diabetes mellitus initiating insulin glargine pen versus vial. Postgrad Med. 2013;125(3):204-13.

15. US Food and Drug Administration. Classify your medical device. Article online. 2014. Available from: http://www.fda.gov/MedicalDevices/Device RegulationandGuidance/Overview/ClassifyYour Device/. Accessed 7 Feb 2017.

16. Spollett G, Edelman S, Mehner P, Walter C, Penfornis A. Improvement of insulin injection technique: examination of current issues and recommendations. Diab Edu. 2016;42(4):379-94.

17. Stacciarini TSG, Pace AE, Haas VJ. Insulin self-administration technique with disposable syringe among patients with diabetes mellitus followed by the family health strategy. Rev Latino-am Enfermagem. 2009;17(4):474-80.

18. De Coninck C, Frid A, Gaspar R, et al. Results and analysis of the 2008-2009 Insulin Injection Technique Questionnaire survey. J Diabetes. 2010;2(3):168-79.

19. Nakatani Y, Matsumura M, Monden T, Aso Y, Nakamoto T. Improvement of glycemic control by re-education in insulin technique in patients with diabetes mellitus. Adv Ther. 2013;30(10):897-906.

20. Arcebido R, Wong E, Cohen V, Likourezos A. Pharmacist-led discharge counseling on subcutaneous insulin use and administration. Am J Health-Syst Pharm. 2013;70(16):1371-3.

21. Iowa Healthcare System. Always use teach-back! Article online. 2015. Available from: http://www. teachbacktraining.org/. Accessed 7 Feb 2017.

22. Institute for Ethics. The Commonwealth Fund. Promising practices for patient-centered communication with vulnerable populations: examples from eight hospitals. Article online. 2006. Available from: http://www.commonwealthfund.org/ / 
media/files/publications/fund-report/2006/aug/pro mising-practices-for-patient-centered-communica tion-with-vulnerable-populations-examples-fromei/wynia_promisingpracticespatientcentered_947pdf.pdf. Accessed 7 Feb 2017.

23. National Quality Forum. Safe practices for better healthcare, 2010 update. A consensus report. Article online. 2010. Available from: http://www.quality forum.org/Publications/2010/04/Safe_Practices_for_ Better_Healthcare_\%E2\%80\%93_2010_Update.aspx. Accessed 7 Feb 2017. 